\title{
POSSIBILIDADES DE SOFRIMENTO PSÍQUICO NO ÂMBITO DO TRABALHO DO PROFESSOR DA PÓS-GRADUAÇÃO STRICTO SENSU
}

\author{
Kelly Cristina Tesche Rozendo ${ }^{1}$, Carmen Lúcia Dias ${ }^{2}$ \\ ${ }^{1}$ Universidade do Oeste Paulista - UNOESTE, ${ }^{1}$ Curso de Psicologia, ${ }^{2}$ Mestrado em Educação, Presidente Prudente, SP. \\ Agência Financiadora: Pibic/CNPq. E-mail: kellytesche@hotmail.com
}

\section{RESUMO}

Esta pesquisa objetivou analisar as possibilidades de sofrimento psíquico de professores universitários dos cursos da pós-graduação stricto sensu, buscando destacar aspectos e características de seu ambiente de trabalho. Os objetivos específicos foram verificar a concepção que estes profissionais têm sobre o exercício da docência; identificar as características que compõem seu ambiente de trabalho; e investigar aspectos da saúde física e mental desses profissionais. $O$ estudo foi realizado segundo a abordagem quanti-qualitativa, do tipo estudo de caso. A metodologia envolveu coleta de dados, por meio de questionário semiestruturado, para professores da pós-graduação stricto sensu, de uma Instituição de Ensino Superior particular do estado de São Paulo. A análise dos dados organizou-se por eixos e categorias. Os resultados apontaram sofrimento psíquico nos professores universitários da pós-graduação, decorrente de aspectos relacionados à organização e às condições de trabalho no contexto acadêmico.

Palavras-chave: Sofrimento psíquico. Trabalho. Professor. Pós-graduação stricto sensu.

\section{POSSIBILITIES OF PSYCHIC SUFFERING IN THE SCOPE AT WORK OF PROFESSOR BY POST- GRADUATE STRICTO SENSU}

\begin{abstract}
This study aimed examine the possibilities of psychic suffering of university professor by postgraduate stricto sensu courses, seeking to emphasize aspects and features of their work environment. The specific objectives were verifying the concept that these professionals have on the practice of teaching; identify the characteristics that make your workplace; and investigate aspects of physical and mental health of these professionals. The research was conducted according to quantitative and qualitative approach, case study type. The methodology involved data collection through questionnaire semi-structured, with professor by post-graduate stricto sensu, in a private Higher Education Institution in the state of São Paulo. A data analysis organized by axes and categories. Results revealed psychic sufferig in university professors by post-graduate, due to aspects related to the organization and labor conditions in the academic context.
\end{abstract}

Keywords: Psychic Suffering. Work. Professor. Post-graduate stricto sensu. 


\section{INTRODUÇÃO}

O mundo do trabalho é um importante fator de satisfação e prazer, sendo uma tarefa que dignifica e humaniza. Porém, esta mesma fonte de prazer pode gerar descontentamentos aos trabalhadores, e segundo sua lógica, produzir sofrimento psíquico e problemas de ordem mental e/ou orgânica. Doenças relacionadas ao trabalho podem ser desencadeadas por condições laborais precárias que levam ao desgaste mental e repercutem em todos os âmbitos da vida. Esse desgaste também pode ser evidenciado em profissionais da educação superior, pois o trabalho docente contemporâneo tem revelado processos de sofrimento psíquico e de adoecimento.

Segundo Araújo et al. (2005) e Lima e Lima-Filho (2009), investigações sobre a relação deste sofrimento com o trabalho podem viabilizar prevenções para diminuição da carga psíquica dos trabalhadores. Apesar disso, o contexto acadêmico propriamente dito, sobretudo, o âmbito da pós-graduação, não possui literatura vasta sobre esta temática (VIEIRA, 2014), o que justificou a relevância desta pesquisa, a qual na tentativa de ampliar estes estudos apresentou como referencial teórico a Psicodinâmica do Trabalho e a Psicologia Social, além de artigos científicos.

No que se refere à Psicodinâmica do Trabalho, esta corrente, tendo como suporte o conhecimento das relações entre trabalho e saúde mental, considera o trabalho no âmbito objetivo e subjetivo. A carga laboral divide-se em carga física e psíquica, englobando visões singulares de cada ser humano. Conforme esta abordagem, o trabalho se relaciona com desgaste mental e pode produzir insatisfação, irritação, exaustão, sofrimento e adoecimento (DEJOURS, 1991; 2004). Já na Psicologia Social, Codo, Sampaio e Hitomi (1993) consideram que o trabalho é parte da história dos seres humanos e cada indivíduo possui individualidade histórica. Codo (1999) afirma que o trabalho imortaliza as ações dos homens. Nesta perspectiva, o trabalho, considerado principal atividade humana, determina o processo de saúde e de doença mental nos indivíduos.

Ambas visões sobreditas concordam que o trabalho é capaz de produzir sofrimento psíquico e adoecimento nos trabalhadores. Nestas perspectivas, o trabalho pode possibilitar ao ser humano a felicidade, a liberdade, mas também a loucura e a doença mental, sendo um fator de importância capital na produção de saúde e doença. Do mesmo modo, pesquisas apontam que o trabalho docente pode evidenciar sofrimento psíquico e adoecimento em seu âmbito laboral (CODO; SAMPAIO; HITOMI, 1993; CODO; SAMPAIO, 1995; CODO, 1999; MENDES et al., 2007; GARCIA; OLIVEIRA; BARROS, 2008; RIBEIRO; MARTINS, 2011).

Decerto, características do processo de trabalho docente aumentam a complexidade, as responsabilidades e as exigências que abarcam a atividade acadêmica. Neste contexto, a relação entre o trabalho e o psiquismo considera repercussões da lógica de produção capitalista. 0 
capitalismo causa desajustes no plano psicológico e traz sofrimento psíquico aos trabalhadores, decorrente das relações de dominação e desumanização presentes no trabalho. Logo, na tarefa dos professores universitários encontram-se contidos elementos capazes de potencializar vivências depressivas que podem se revelar nas esferas psíquica, física e social (CODO, 1999; ESTEVE, 1999; DEJOURS, 2004; ARAÚJO et al., 2005; MENDES et al., 2007; GARCIA; OLIVEIRA; BARROS, 2008; LIMA; LIMA-FILHO, 2009; GRADELLA, 2010; SERVILHA; ARBACH, 2011; CASSANDRE, 2011; JILOU, 2013; BERNARDO, 2014).

Diante disto, pretendeu-se por meio deste estudo, como objetivo geral, analisar as possibilidades de sofrimento psíquico dos professores universitários da pós-graduação stricto sensu, buscando destacar aspectos e características de seu ambiente de trabalho. Especificamente, buscou-se verificar a concepção que estes profissionais têm sobre o exercício da docência; identificar as características que compõem seu ambiente de trabalho; e investigar aspectos da saúde física e mental dos professores universitários da pós-graduação stricto sensu.

\section{METODOLOGIA}

A presente pesquisa, inscrita na Coordenadoria Central de Pesquisa (CCPq/UNOESTE) sob protocolo número 2052, agência financiadora PIBIC/CNPq, foi realizada segundo a abordagem quanti-qualitativa, do tipo estudo de caso. Após aprovação do Comitê de Ética em Pesquisa e assinatura do Termo de Consentimento Livre Esclarecido (TCLE) pelos sujeitos, a coleta de dados realizou-se por meio de questionário semiestruturado para dezessete professores dos cursos de pós-graduação stricto sensu, de uma Instituição de Ensino Superior (IES) particular do estado de São Paulo. O critério de escolha dos participantes foi por sorteio, ou seja, $30 \%$ do total de 55 professores, garantindo a representatividade, a não identificação e o sigilo dos sujeitos. Os dados obtidos foram analisados e trabalhados quantitativamente, por meio da descrição de dados estatísticos e, qualitativamente, por meio da análise de conteúdo apresentada por Bardin (2011), que consiste na interpretação do significado das respostas dos pesquisados. Os dados foram organizados por eixos e categorias, e relacionados com os objetivos propostos por essa pesquisa.

\section{RESULTADOS}

A partir dos dados coletados, foram instituídos eixos e categorias. O Eixo l, ao referir-se a concepção sobre o exercício de docência, verificou, por meio de categorias, aspectos relacionados à importância da docência; inserção na carreira docente; requisitos necessários para o exercício da docência; e importância da Pesquisa/Extensão/Iniciação Científica na atuação docente. O Eixo /I 
abordou o ambiente de trabalho na universidade e investigou o impacto das novas leis de mercado e dos avanços tecnológicos na universidade e na docência, bem como, analisou as condições laborais oferecidas pela universidade; a liberdade e autonomia no desenvolvimento do trabalho; a sobrecarga de trabalho; a competição no trabalho, a remuneração e o reconhecimento da profissão de docência. O Eixo III, ao tratar da saúde física e mental do professor universitário, averiguou fatores relacionados ao docente gostar do que faz; relações sociais no trabalho; correspondência entre exigências externas/internas no trabalho; separação entre trabalho e vida privada; tempo fora do trabalho; hábitos de vida; e mormente, as relações entre o trabalho e a saúde e entre o trabalho e o sofrimento psíquico.

\section{DISCUSSÃO}

Conjecturando que o mundo do trabalho pode desencadear sofrimento psíquico nos profissionais inseridos em diferentes contextos da universidade, inclusive na pós-graduação, este estudo delineou como propósito central analisar as possibilidades de sofrimento psíquico dos professores universitários da pós-graduação stricto sensu, buscando destacar aspectos e características de seu ambiente de trabalho. Os objetivos específicos foram verificar a concepção que estes profissionais têm sobre o exercício da docência, identificar as características que compõem seu ambiente de trabalho, e investigar aspectos da saúde física e mental dos professores universitários da pós-graduação stricto sensu. A partir disso, os dados aportados por esta pesquisa foram organizados por eixos e categorias.

Ponderando as categorias do Eixo I - Concepção sobre o exercício de docência - é importante frisar que os professores universitários dos cursos de pós-graduação stricto sensu, possuem uma visão abrangente e consciente sobre a relevância de sua profissão perante a sociedade, tendo em vista suas considerações pautadas em uma ação voltada a um processo de formação amplo e geral, capaz de desenvolver cidadãos e mobilizar transformações sociais.

A ideia da docência ligada à sociedade vem ao encontro de Libâneo (1994), cuja visão considera a prática educativa necessária para o funcionamento das sociedades, sendo um fenômeno social e universal. Nesta mesma linha, Masetto (2003) aponta que a docência é tida como um dos pilares na formação cidadã. Ser professor requer assumir a missão e o compromisso contínuo de educar os indivíduos para a construção e para a edificação dos saberes. Para Codo (1999), a docência consiste em um trabalho completo, raro e artesanal.

No Eixo II - Ambiente de trabalho na universidade - os dados aportados, mediante categorias, revelam que as modificações sofridas no mundo do trabalho acadêmico, impostas pelo 
sistema capitalista, refletem exigências rigorosas na atuação dos professores. O ambiente de trabalho é avaliado pelos sujeitos dessa pesquisa, como precário, inadequado, competitivo, vigiado e munido de pressões e ameaças, sendo que os professores universitários da pósgraduação stricto sensu descrevem pontos negativos e deficitários relacionados a recursos físicos, materiais e humanos oferecidos pela IES, confirmando investigações de Lima e Lima-Filho (2009), que revelam deficiências no ambiente acadêmico e na organização laboral das universidades. $A$ propósito, o professor universitário experimenta o sofrimento psíquico relacionado à precarização das condições e do ambiente de trabalho (GRADELLA, 2010; BERNARDO, 2014).

Contudo, Dejours, Dessors e Desriaux (1993) afirmam que flexibilizar a organização do trabalho e dar ao trabalhador liberdade e autonomia possibilita a diminuição da carga psíquica. À vista disto, é relevante o fato de que $100 \%$ dos professores universitários da pós-graduação stricto sensu possuem liberdade no trabalho e $88 \%$ possuem autonomia para desenvolver suas tarefas na universidade. No entanto, estes trabalhadores demonstram inúmeras insatisfações com o contexto laboral acadêmico. Os professores universitários se sentem sobrecarregados no trabalho, descrevem competição exacerbada na universidade, e estão insatisfeitos com a retribuição financeira oferecida pela instituição, sendo que muitos docentes consideram que seu trabalho não é reconhecido pela IES e tampouco pela sociedade de modo geral (GARCIA; OLIVEIRA; BARROS, 2008; LIMA; LIMA-FILHO, 2009; FONTANA; PINHEIRO, 2010; BERNARDO, 2014).

Para Gradella (2010) e Jilou (2013), o trabalho caracterizado por competição, conflitos, rigidez, controle e desvalorização promove sobrecargas físicas, cognitivas e afetivas, resultando em fatores desgastantes para os professores. Segundo Lima e Lima-Filho (2009), essa dinâmica de trabalho traz consequências como estresse, cansaço, ansiedade, fobias, depressão e transtornos psicossomáticos. Portanto, pode-se inferir que o ambiente e a organização do trabalho dos professores universitários dos cursos de pós-graduação stricto sensu, possuem aspectos e características que promovem insatisfações, sobrecargas, frustrações e desgastes, capazes de desencadear sofrimento psíquico e adoecimento nos profissionais de educação superior.

De fato, o trabalho apresenta pontos negativos, entretanto, Dejours (2004) lembra que o labor também radica fatores positivos. Na presente pesquisa, dentre os aspectos positivos da docência encontram-se os vínculos sociais, autonomia, liberdade, ambiente favorável e atividades vinculadas à pesquisa. Já entre os pontos negativos, destacam-se a infraestrutura física e humana, conflitos, apoio técnico, científico e financeiro insuficiente, cobranças, pressões, burocracia, sobrecarga de trabalho e falta de reconhecimento. Tais fatores contribuem para o surgimento de 
sofrimento psíquico nos professores, podendo refletir na saúde física e mental desses trabalhadores (CODO, 1999; MENDES et al., 2007; RIBEIRO; MARTINS, 2011; CASSANDRE, 2011).

As categorias do Eixo III - Saúde física e mental do professor universitário - enfatizaram o trabalho como um relevante fator de adoecimento, sofrimento mental e crescente manifestação de distúrbios (DEJOURS, 1991, 2004; CODO, SAMPAIO; HITOMI, 1993; CODO; SAMPAIO, 1995; CODO, 1999). No presente estudo, a maioria dos professores universitários da pós-graduação stricto sensu acredita que a profissão de docência pode fazer emergir sofrimento psíquico, bem como, encontrase correlacionada com a saúde física e mental. Tais posicionamentos legitimam pesquisas que descrevem o trabalho docente como importante desencadeante de sofrimento e adoecimento (CODO, 1999; MENDES et al., 2007; GRADELLA, 2010; RIBEIRO; MARTINS, 2011; JILOU, 2013).

Araújo et al. (2005) e Gradella (2010) postulam que os professores universitários evidenciam enfermidades após o ingresso na carreira acadêmica, fato corroborado por vários participantes dessa pesquisa, que afirmam que desenvolveram problemas de saúde após ingressarem na carreira acadêmica, apresentando sintomas e/ou episódios, tais como, vertigens, dores pelo corpo, cansaço físico e mental, estresse, baixa imunidade, quadros ansiosos, insônia, depressão, gastrite, irritação, cefaleias, dores no estomago, tonturas, entre outras manifestações de sofrimento.

Jilou (2013) constatou que o sofrimento dos professores universitários está relacionado à ansiedade, estresse, cansaço, frustração, entre outras queixas e insatisfações. Para os docentes desta pesquisa, o trabalho associa-se ao sofrimento psíquico quando caracterizado por conflitos, desgostos, insatisfações, desvalorização, frustrações, pressões, sobrecarga laboral, estresse, depressão, fobias, etc. Fatores esses, presentes nas universidades, e capazes de promover sofrimento e refletir negativamente na saúde física e mental dos profissionais da educação.

A partir disto, pode-se inferir que há aspectos na saúde física e mental dos professores universitários da pós-graduação stricto sensu que supõem a presença de sofrimento psíquico no âmbito laboral, decorrente de fatores que compõem o ambiente e as condições de trabalho destes profissionais. Cabe salientar que Mendes et al. (2007) revelam que o sofrimento psíquico dos professores universitários pode ser aliviado por meio de suporte social. Prontamente, as relações sociais foram descritas pelos participantes desta pesquisa, como boas e prazerosas, munidas de respeito e cordialidades, revelando um clima agradável e amistoso na universidade. Para Codo (1999), a qualidade das relações sociais estabelecidas no trabalho serve de proteção e manutenção da saúde mental dos professores.

De acordo com Dejours (1991) e Lima e Lima-Filho (2009), a saúde dos professores universitários é afetada ainda por um embate entre a história individual e o mundo do trabalho, o 
qual ignora os desejos, as esperanças e os objetivos dos indivíduos, podendo promover sofrimento psíquico. Neste sentido, a maioria dos professores universitários da pós-graduação stricto sensu revela que o trabalho na IES corresponde a seus desejos, anseios e aspirações, ainda que revelem insatisfações. Não obstante, $12 \%$ dos sujeitos deste estudo, afirmam que o trabalho não coincide com seus desejos internos, revelando desgostos e sofrimento no contexto laboral acadêmico.

Este sofrimento, segundo Araújo et al. (2005), não se limita apenas ao mundo do trabalho, mas vai se construindo e interferindo nas funções gerais da vida, influenciando de maneira negativa a saúde mental e física dos trabalhadores. Os reflexos do trabalho invadem a vida privada dos docentes. Entrementes, mais da metade da amostra afirma que consegue separar a vida profissional da vida privada, no entanto, a maioria assume que leva trabalhos da instituição para fazer em casa. Ao estender o trabalho para o ambiente pessoal, o professor derruba as barreiras entre o mundo pessoal e o profissional, extrapolando os limites que deveriam permanecer para colaborar com a diminuição da carga psíquica (CODO, 1999; GARCIA; OLIVEIRA; BARROS, 2008).

\section{CONCLUSÃO}

Esta pesquisa enfocou pontos significativos que atingem o âmbito laboral acadêmico e que influenciam no surgimento de sofrimento psíquico de professores universitários. Os dados coletados foram organizados por eixos e categorias, respeitando os objetivos propostos por esse estudo. O Eixo I revelou uma concepção abrangente dos professores dos cursos da pós-graduação stricto sensu sobre sua profissão perante a sociedade, considerando-a parte de um processo de formação geral capaz de mobilizar transformações sociais. O Eixo II identificou características do ambiente de trabalho dos professores universitários que promovem insatisfações, sobrecargas, tensões, frustrações e desgastes. O Eixo III, ao investigar a saúde física e mental dos docentes, revelou sintomas relacionados a episódios de cansaço excessivo, estresse, depressão, entre outros. A partir disto, pode-se inferir que o trabalho dos professores universitários da pósgraduação stricto sensu pode desencadear sofrimento psíquico e trazer consequências negativas para a saúde física e mental destes profissionais.

\section{REFERÊNCIAS}

ARAÚJO, T. M.; SENA, I. P.; VIANA, M. A.; ARAÚJO, E. M. Mal-estar docente: avaliação de condições de trabalho e saúde em uma instituição de ensino superior. Revista Baiana de Saúde Pública, v. 29, n.1, p. 6-21, jan./jun. 2005.

BARDIN, L. Análise de conteúdo. Tradução Luis Antero Reto, Augusto Pinheiro. São Paulo: Edições 70, 2011. 
BERNARDO, M. H. Produtivismo e precariedade subjetiva na universidade pública: o desgaste mental dos docentes. Psicologia \& Sociedade, v. 26, n. spe., p. 129-139, 2014.

CASSANDRE, M. P. A saúde de docentes de pós-graduação em universidades públicas: os danos causados pelas imposições do processo avaliativo. Revista Mal-estar e Subjetividade, Fortaleza, v. 11, n. 2, p. 779-816, 2011.

CODO, W.; SAMPAIO, J. J. C. HITOMI, A. H. Indivíduo, trabalho e sofrimento: uma abordagem interdisciplinar. Petrópolis: Vozes, 1993.

CODO, W.; SAMPAIO, J. (Orgs.). Sofrimento Psíquico nas Organizações. Petrópolis: Vozes, 1995.

CODO, W. (Org.). Educação: carinho e trabalho. Universidade de Brasília, Laboratório de Psicologia do Trabalho. Petrópolis: Vozes, 1999.

DEJOURS, C. A loucura do trabalho: estudo de psicopatologia do trabalho. 4. ed. São Paulo: Cortez, 1991.

DEJOURS, C. Subjetividade, trabalho e ação. Revista Produção, v. 14, n. 3, p. 27-34, set./dez. 2004.

DEJOURS, C.; DESSORS, D.; DESRIAUX, F. Por um trabalho, fator de equilíbrio. Rev. de Adm.

Empres, São Paulo, v. 33, n. 3, p. 98-104, maio/jun. 1993. http://dx.doi.org/10.1590/s0103$\underline{65132004000300004}$

ESTEVE, J. M. O mal-estar docente: a sala de aula e a saúde dos professores. Tradução Durley de Carvalho Cavicchia. Bauru, SP: EDUSC, 1999.

FONTANA, R. T.; PINHEIRO, D. A. Condições de saúde auto-referidas de Professores de uma universidade regional. Rev Gaúcha Enferm., Porto Alegre/RS, v. 3, n.2, p. 270276, jun., 2010.

GARCIA, A. L.; OLIVEIRA, E. R. A.; BARROS, E. B. Qualidade de vida de professores do ensino superior na área da saúde: discurso e prática cotidiana. CogitareEnferm, 13(1), p. 18-24, jan./mar. 2008. http://dx.doi.org/10.5380/ce.v13i1.11945

GRADELLA, O. J. Sofrimento psíquico e trabalho intelectual do docente universitário. Cadernos de psicologia social do trabalho, Marília, v. 13, n. 1, p. 133-148, 2010.

JILOU, V. Capitalismo flexível, trabalho precarizado e sofrimento psíquico de professores universitários. Revista Encontro de Pesquisa em Educação, Uberaba, v. 1, n. 1, p. 187-201, 2013.

LIBÂNEO, J. C. Didática. São Paulo: Cortez, 1994.

LIMA M. F. E. M.; LIMA-FILHO D. O. Condições de trabalho e saúde do/a professor/a universitário/a. Ciências \& Cognição, v. 14, n. 3, p. 62-82, 2009.

MASETTO, M. T. Competência pedagógica do professor universitário. São Paulo: Summus, 2003. 
MENDES, L.; CHAVES, C. J. A.; SANTOS, M. C.; NETO, G. A. M. Da arte ao ofício: vivências de sofrimento e significado do trabalho de professor universitário. Rev. Mal-estar e subjetividade, Fortaleza, v. 7, n. 2, p. 527-556, set. 2007.

RIBEIRO, S. F. R.; MARTINS, S. T. F. Sofrimento psíquico do trabalhador da saúde da família na Organização do Trabalho. Psicologia em estudo, Maringá, v. 16, n. 2, p. 241-250, abr./jun. 2011.

SERVILHA, E. A. M.; ARBACH, M. P. Queixas de saúde em professores universitários e sua relação com fatores de risco presentes na organização do trabalho. DistúrbComum, São Paulo, 23(2), p. 181-191, ago. 2011.

VIEIRA, S. R. S. Sofrimento psíquico e trabalho. Rev. Latinoam. Psicopat. Fund., São Paulo, v. 17, n. 1, p. 114-124, mar. 2014. 